\title{
Amphioxus mouth after dorso-ventral inversion
}

Takao Kaji ${ }^{1,2}$, James D. Reimer ${ }^{3}$, Arseniy R. Morov ${ }^{1,4}$, Shigeru Kuratani ${ }^{5}$ and Kinya Yasui ${ }^{1 *}$ (D

\begin{abstract}
Introduction: Deuterostomes (animals with 'secondary mouths') are generally accepted to develop the mouth independently of the blastopore. However, it remains largely unknown whether mouths are homologous among all deuterostome groups. Unlike other bilaterians, in amphioxus the mouth initially opens on the left lateral side. This peculiar morphology has not been fully explained in the evolutionary developmental context. We studied the developmental process of the amphioxus mouth to understand whether amphioxus acquired a new mouth, and if so, how it is related to or differs from mouths in other deuterostomes.

Results: The left first somite in amphioxus produces a coelomic vesicle between the epidermis and pharynx that plays a crucial role in the mouth opening. The vesicle develops in association with the amphioxus-specific Hatschek nephridium, and first opens into the pharynx and then into the exterior as a mouth. This asymmetrical development of the anterior-most somites depends on the Nodal-Pitx signaling unit, and the perturbation of laterality-determining Nodal signaling led to the disappearance of the vesicle, producing a symmetric pair of anterior-most somites that resulted in larvae lacking orobranchial structures. The vesicle expressed bmp2/4, as seen in ambulacrarian coelomic pore-canals, and the mouth did not open when Bmp2/4 signaling was blocked.

Conclusions: We conclude that the amphioxus mouth, which uniquely involves a mesodermal coelomic vesicle, shares its evolutionary origins with the ambulacrarian coelomic pore-canal. Our observations suggest that there are at least three types of mouths in deuterostomes, and that the new acquisition of chordate mouths was likely related to the dorso-ventral inversion that occurred in the last common ancestor of chordates.
\end{abstract}

Keywords: Lancelet, Homology of mouth, Coelom, Hydropore, Nodal-signaling, Gill (branchial) slits

\section{Introduction}

The mouth opening is evolutionarily related to the blastopore, the first opening to connect the gut and exterior during development. In cnidarians, gastrulation occurs at the animal pole and the blastopore directly gives rise to the mouth/anus [1]. In contrast, in most bilaterians, the blastopore forms at the vegetal pole, and primarily determines the anteroposterior body axis [2]. As the blastopore is at the posterior in their developmental system, bilaterians exhibit various patterns of mouth formation in the anterior body.

Some protostomes utilize the blastopore as the mouth after shifting the blastopore towards the anterior during development [3, 4], which is referred to as

\footnotetext{
* Correspondence: furaha@sci.hiroshima-u.ac.jp

'Department of Biological Science, Graduate School of Science, Hiroshima University, 1-3-1 Kagamiyama, Higashi-hiroshima, Hiroshima 739-8526, Japan Full list of author information is available at the end of the article
}

protostomy. In contrast, deuterostome ambulacrarians (echinoderms + hemichordates) and chordates open their mouths independently of the blastopore, a process called deuterostomy. The new setting of the oral site in ambulacrarian larvae is suggested to be caused by the separation of mouth-forming gene regulatory networks (GRN) from the ancestral blastoporal GRN that specifies mouth formation, axis determination, and germ layer specification [5]. This uncoupling with a gene set comparable to ambulacrarians is also found in protostome animals $[5,6]$ and thus seems to represent an ancestral state.

Vertebrates, however, do not share the ancestral mouthforming GRN with other animals [7], and also have an interesting dorso-ventral axis characterized by Bmp expression on one side and Chordin, a repressor of Bmp signaling, expression on the other. The vertebrate mouth opens on the Bmp-expressing side, whereas non-chordate bilaterians have mouths on the Chordin-expressing side 
[8]. Among chordates, amphioxus exhibits a further unique pattern, in which the mouth initially opens on the left, despite a streamlined body shape (Fig. 1a, b). This asymmetrical mouth opening appears at early larval stages along with other pharyngeal structures, such as the lateral diverticula, mucus-secreting glands, and gill openings (Fig. 1c). The unusual location of the amphioxus larval mouth is a longstanding enigma, and various hypotheses have been put forth in an effort to homologize the amphioxus mouth to structures in other animals. (1) The amphioxus mouth is derived from the first left gill pore, thereby being homologous to the vertebrate spiracle [9-11], (2) it is homologous to the mid-ventrally located mouth of most bilaterians, which in amphioxus moved to the left side due to adaptation from a proposed past epibenthic life mode [12], or (3) it is homologous to the mid-dorsally located larval ascidian mouth that in amphioxus has moved to the left due to anterior elongation of the notochord [13, 14]. The last two hypotheses are based on the idea that all animal mouths are homologous. It has also been suggested, alternatively, that the amphioxus mouth is a novel trait uniquely acquired in the cephalochordate lineage [15]. All of these ideas are attractive but remain unverified.

In this study, we identified a coelomic vesicle that developed from the posterior wall of the left anterior- most somite. This vesicle accompanies the Hatschek nephridium and contributes to the formation of the larval mouth. The oral development of amphioxus was controlled under the evolutionarily conserved Nodal-Pitx signaling unit [16-18] on the left side and has no relation to the mouth-forming GRN found in ambulacrarians and protostomes. The developmental process of the amphioxus mouth strongly suggests its similarity to that of ambulacrarian coelomic pore-canals and their common evolutionary origin. Thus the amphioxus mouth is distinct from olfactorean (urochordates and vertebrates) [19] mouths that develop from a specific region called the anterior pan-placode at the anterior extremity of the body [7] or its equivalent [20]. We suggest that deuterostomes display at least three types of different mouths, of which at least two types have been acquired by chordates, all developing independently of the blastopore.

\section{Materials and methods}

Experimental animals

Amphioxus specimens studied in the present research were from a Japanese population of Branchiostoma japonicum (formerly B. belcheri) [21, 22]. All embryos and larvae were collected during breeding season from first laboratory generations bred by parental animals collected from a wild habitat in the Ariake Sea, Japan, that were
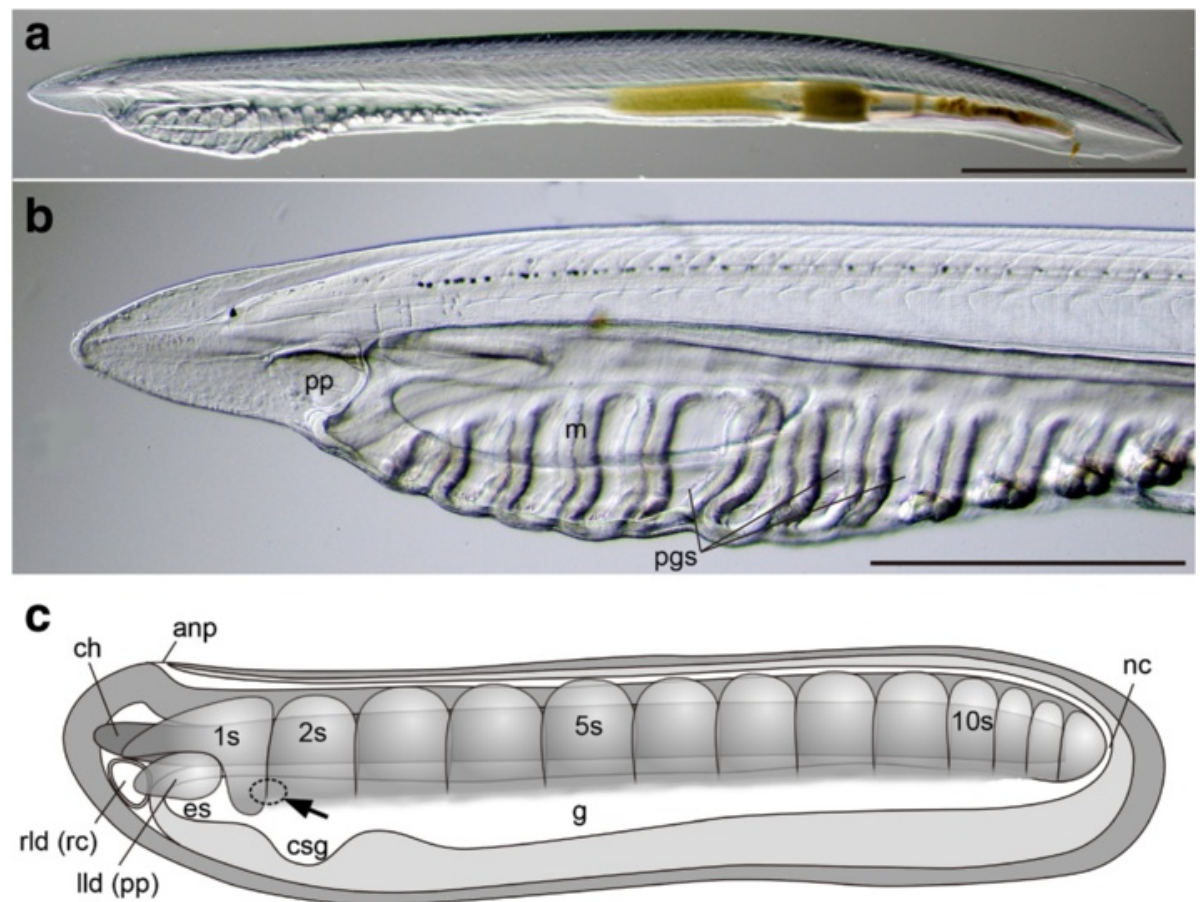

Fig. 1 Larval asymmetry of amphioxus. a Left lateral view of premetamorphic larva showing streamlined shape. b Magnification of oral region showing mouth and preoral pit on left and gill openings on right side. c Schematic illustration of early knife-shaped larva showing organ formation in anterior region and previously suggested location of mouth opening (arrow). anp; anterior neuropore; ch, notochord; csg, primordial club-shaped gland; es, primordial endostyle; g, gut; Ild, left lateral diverticulum (= pp, preoral pit); m, mouth; nc, neurenteric canal; pgs, primary gill slit; rld, right lateral diverticulum (= rc, rostral coelom); 1-10s, 1st-10th somite. Scale bars, $1.0 \mathrm{~mm}$ for (a), $0.5 \mathrm{~mm}$ for (b) 
then maintained in a laboratory culture system [22]. The amphioxus colony is maintained and all embryos and larvae subjected to the present study were manipulated according to guidelines established by Hiroshima University for the care and use of experimental animals.

\section{Preparation of RNA probes for whole-mount in situ hybridization}

In total seven DNA fragments encoding the coding region of seven genes were amplified by PCR with primer sets listed in Table 1. Template cDNA for PCR was constructed from a frozen sample of spawn at the neurula stage with 7-9 somites by using ISOGEN (Nippon Gene, Japan) for isolating total RNA, and SMARTer RACE cDNA Amplification Kit (Clonetech, California) for constructing first strand cDNA. Amplicons were cloned into the pGEM-T Easy vector (Promega, Wisconsin) and sequenced to confirm identity. Digoxigenin- or fluorescein-labeled antisense riboprobes were synthesized by SP6 or T7 RNA polymerase (Roche Applied Science, Germany).

\section{Whole-mount in situ hybridization (WISH)}

Embryos and larvae for WISH were fixed at $4{ }^{\circ} \mathrm{C}$ overnight with freshly prepared $4 \%$ paraformaldehyde in $0.1 \mathrm{M}$ 3-(N-morpholino) propanesulfonic acid (MOPS) buffer, pH 7.5, containing $0.5 \mathrm{M} \mathrm{NaCl}$, then washed with $50 \%$ ethanol, and stored in $75 \%$ ethanol at $-20{ }^{\circ} \mathrm{C}$ until use. WISH was performed with a setting temperature of $60{ }^{\circ} \mathrm{C}$ for prehybridization and hybridization according to previously described protocol [23]. Expression patterns were observed after changing solution from phosphate buffered saline (PBS, pH 7.4) to $80 \%$ glycerol in PBS. To obtain rendering images of confocal laser scanning microscopy (LSM), double fluorescence WISH was performed with anti-sense riboprobes for mef2 and pou 4 or pax3/7. Anti-DIG-POD (Roche Applied Science, Germany) and anti-fluorescein-POD (PerkinElmer, Massachusetts) antibodies were used to detect the anti-sense riboprobes and then the TSA Plus Cyanine 3 \& Fluorescein system
(PerkinElmer, Massachusetts) was utilized to amplify the fluorescent signal [24]. For diffusion of labeled fluorescein into the whole body, labeled specimens were stored in $80 \%$ glycerol in PBS for more than one month in dark at $4{ }^{\circ} \mathrm{C}$. Subsequently, rendering images were obtained by using an LSM (ECLIPS C1, Nikon, Japan).

\section{Semi-thin plastic sections and transmission electron microscopy (TEM)}

Larvae for TEM were fixed with $1.25 \%$ glutaraldehyde and $1 \%$ paraformaldehyde in Millipore filtered seawater (MPFSW) at $4{ }^{\circ} \mathrm{C}$ overnight. Fixed specimens were washed twice with MPFSW and stored in MPFSW with a few drops of the same fixative as for WISH at $4{ }^{\circ} \mathrm{C}$. After washing with MPFSW, specimens were subjected to a conductive staining with $1 \%$ tannic acid in MPFSW for $30 \mathrm{~min}$ at $4{ }^{\circ} \mathrm{C}$, washed with MPFSW, and then postfixed with $1 \%$ osmium tetroxide for 1 hour at $4{ }^{\circ} \mathrm{C}$. Postfixed specimens were dehydrated conventionally, then passed through pure propylene oxide, and finally embedded into Epon 812 following a previous study [25]. Knife-shaped larvae fixed at various times (24-30 hours post fertilization (hpf) at $25^{\circ} \mathrm{C}$ ) were transversely serially cut at $1-\mu \mathrm{m}$ thickness and stained with toluidine blue to optically observe the developmental changes of the anterior part of the body. Based on observation of the semi-thin sections, appropriate specimens in resin were trimmed into blocks for TEM observation with a JEM1400 (JEOL, Japan) at Hiroshima University.

\section{Fluorescent immunostaining}

Specimens for immunostaining were obtained from those fixed for WISH. Antibodies used for detecting nerves, ventral muscles, and basal laminae were anti-acetylated tubulin antibody (T6793, Sigma-Aldrich, Missouri), anti$\alpha$ SM1 antibody (NCL-SMA, Leica, UK), and anti-laminin antibody (L9393, Sigma-Aldrich, Missouri), respectively. The antibodies were diluted to 1/200 with Can Get Signal (Toyobo, Japan). As secondary antibodies, anti-mouse or

Table 1 List of forward and reverse primer sets for PCR amplification

\begin{tabular}{|c|c|c|c|c|}
\hline Name of gene & Forward primer & Reverse primer & Accession no. & Reference \\
\hline$d k k 1 / 2 / 4$ & CCGTAACTTGTCCACACCGTAGA & GTGCTTTGATGCGTCTTGTTGGG & HM590023 & Zhang and Mao (2010) [35] \\
\hline$f r z b 1^{a)}$ & GTGGTTCCTCCCGTTGTTG & GCTTCAGCCGTCTITCCCA & XM002612836 & Putnam et al. (2008) [52] \\
\hline $\lim 1 / 5^{\mathrm{b})}$ & AGGGACTCCAAACTGTACTG & TTACCACACCGACTCTTCC & DQ399521 & Langeland et al. (2006) [30] \\
\hline mef2 ${ }^{c}$ & GCTTATGAGCTGAGTGTGCT & GGTTCACTCTTGATCTGCAT & EF407505 & Zhang et al. (2007) [53] \\
\hline$p a \times 2 / 5 / 8$ & TGTGACAACGACACAGTTCC & AACAGCAACTGGATAGTGGC & AB193513 & Hiruta et al. (2005) [54] \\
\hline$p a \times 3 / 7^{d)}$ & GGTGGAGAAGAAGATAGAGG & ACGGATGTTCAGTACGCTTG & XM002610760 & Holland et al. (1999) [55] \\
\hline pou4 ${ }^{\mathrm{e})}$ & ACAACACATCAGCATGCACC & GGTTTGTITTGACCGTTATT & DQ314242 & Candiani et al. (2006) [28] \\
\hline
\end{tabular}

Sequences of Branchiostoma japonicum gene fragments were registered under accession numbers ${ }^{\text {a) }} A B 979875,{ }^{\text {b) }} A B 980198,{ }^{\text {c) }} A B 980199,{ }^{d)} A B 980200$, and ${ }^{\text {e) }} \mathrm{AB980202}$ 
-rabbit IgG antibodies labeled with Alexa Fluor 488 or 594 (Life Technologies, California) were used at 1/500 dilution. Specimens immunoreacted with the antilaminin antibody were also stained DNA with Hoechst (Life Technologies, California) at $5 \mu \mathrm{g} / \mathrm{ml}$ while washing the secondary antibody. Fluorescent images were obtained as optical sections or rendering images that covered more than half an amphioxus body width by using an LSM (ECLIPS C1, Nikon, Japan).

\section{Pharmacological treatments}

To block Nodal signaling, embryos were treated with SB505124 (S4696, Sigma-Aldrich, Missouri) [26] at $5 \mu \mathrm{M}$ in MPFSW from the prehatching early neurula stage to the hatching neurula stage (2 hours from $10 \mathrm{hpf}$ at $\left.25^{\circ} \mathrm{C}\right)$. The treatment was stopped by washing twice with MPFSW. Dorsomorphin (045-31221, Wako, Japan) was used to perturb BMP signaling before the mouth opened [27]. The treatments at 5-, 10-, and 25- $\mu \mathrm{M}$ concentrations were started at the knife-shaped larval stage $(24 \mathrm{hpf}$ at $25{ }^{\circ} \mathrm{C}$ ) and stopped at $30 \mathrm{hpf}$. Treated specimens and those reared in MPFSW with the same volume of dimethyl sulfoxide added were fixed under the same protocol as for WISH specimens at 16, 24, 36, and 66 hpf for Nodal-blocked specimens and $72 \mathrm{hpf}$ for BMP-blocked specimens.

\section{Image data processing}

Digital images in JPEG or TIFF format were obtained by an optical microscope (TE2000, Nikon, Japan), LSM (ECLIPS C1, Nikon, Japan), or TEM (JEM1400, JEOL, Japan). They were visually optimized and edited with Adobe Photoshop and Illustrator CS6 (Adobe, California).

\section{Results and discussion}

To identify the positional specification for mouth opening, we initially focused on the expression of the transcription factor gene pou4, which is reported to be expressed in the oral region including within a cell mass under the epidermis at the early larval stage, as well as at the margin of the mouth during perforation [28]. We observed a vesicle between the left first and second somite in optical horizontal sections of larvae that visualized pou4 expression, confirming that the pou4expressing subepidermal cell mass is a vesicle (Fig. 2a, b). By tracing pou4 expression during early larval development, we confirmed a connection between the vesicle and the left first somite at the earliest larval stage (Fig. 2a, b). The vesicle was subsequently isolated from the somitic cavity and opened into the pharynx. The vesicle was then incorporated into the pharyngeal endoderm while maintaining tight contact with the epidermis (Figs. 2c, d and $3 \mathrm{~d}, \mathrm{e})$. The perforation of the mouth occurred between the epidermis and the vesicle remnant that still expressed pou4 (Fig. 2d).

To further understand the developmental process of the vesicle formation, we performed fluorescent WISH with $p a x 3 / 7$, an upstream muscle specification gene [29], and pou4 probes for a developmental series of early larvae. Fluorescent rendering images of LSM clarified that the vesicle developed from the posterior ventral corner of the left first somite (Fig. 2e-g). The posterior wall first became thickened and bulged ventrally at the late neurula stage (18-20 hpf at $\left.25{ }^{\circ} \mathrm{C}\right)$. The thickened wall expressed pax3/7, and subsequently the ventral bulge was extruded from the wall, incorporating the somitocoelic lumen as a vesicle, and began to express pou4 (Fig. $2 \mathrm{e}-\mathrm{g}$ ). In the pax3/7-expressing region, a canal newly formed to connect the somitocoel and cavity of the vesicle. These observations confirmed that this vesicle (hereafter referred to as oral mesovesicle, OMV) is mesodermal as previously suggested [30,31], and that the OMV is the definitive source of the larval mouth in amphioxus.

Within the above-noted canal, TEM observations identified cell(s) bearing a flagellum with a whorl of microvilli, a character of amphioxus excretory cells called cyrtopodocytes [32] (Fig. 3f, g). The canal initially opened into the pharynx through the cavity of the OMV. Our observations highlight the close developmental relationship between the Hatschek nephridium (Hn) and the mouth in amphioxus, although classical studies inferred that the mouth opened independently from the bulge of the left first somite even as they described the bulge $[9,33]$.

The primordial oral site in vertebrate embryos commonly appears as a median pan-placode at the anterior extremity of the body, and the pan-placode contains the olfactory, pituitary, and stomodaeum subdomains from the dorsal to ventral direction [7]. The stomodeal ectoderm is directly in contact with the underlying endoderm without any intervening mesodermal cells, and dissolves the basal lamina between itself and the pharyngeal endoderm to form an oropharyngeal membrane that opens to the exterior as a mouth [7]. Since the dissolution of basal laminae is essential for fusion and intercalation between the two epithelia, we examined this by TEM observations and immunolabeling with an anti-laminin antibody.

When the OMV became an isolated vesicle, it was tightly in contact with both the epidermis and endoderm without any basal laminae as in the vertebrate stomodaeum, as confirmed by the TEM observations and immunostaining against laminin (Fig. 3a-c, f, g). The cell mass of the Hatschek nephridium mounted the OMV and developed basal lamina on the surface except in the area in contact with the OMV (Fig. 3c, f). The perforation between the OMV and pharynx occurred without intercalation of the two epithelia, but the OMV appeared to be incorporated into the pharyngeal endoderm (Fig. 3d, e). 

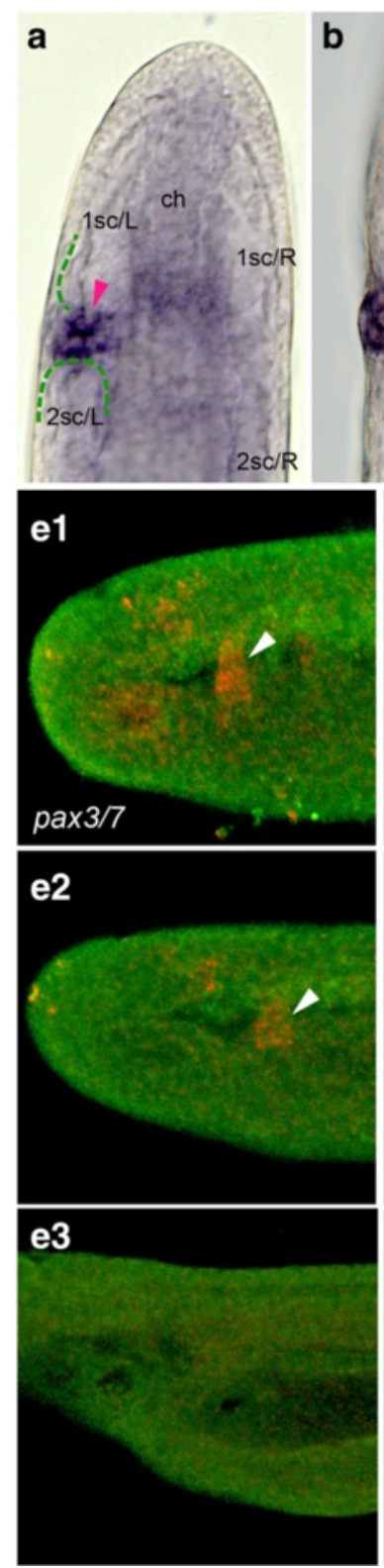

b

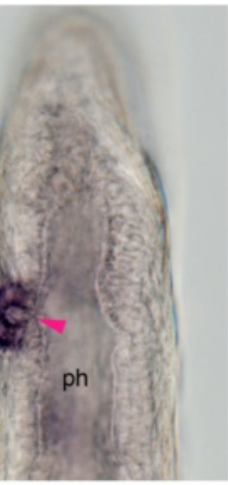

f1

pou4

f2

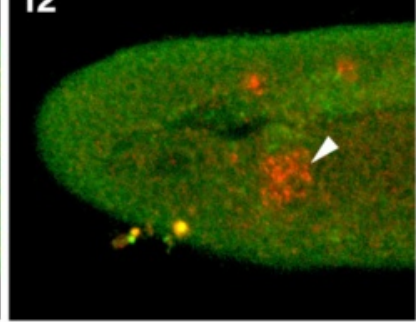

f3

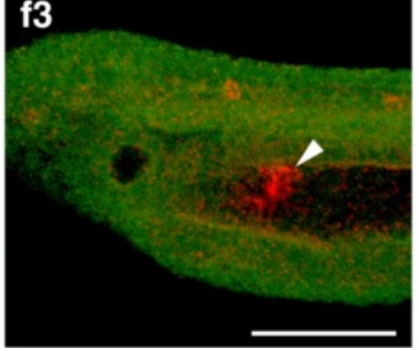

c

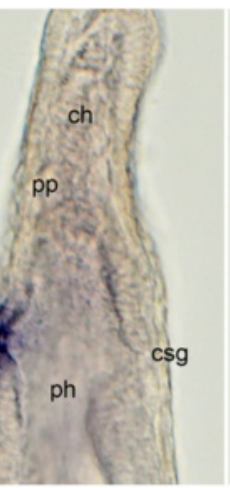

d

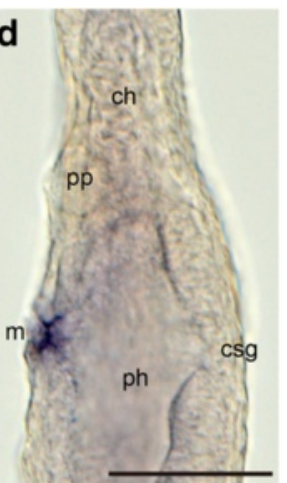

g1

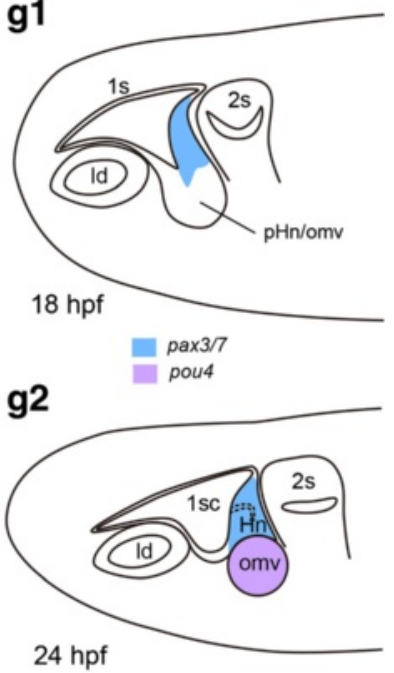

g3

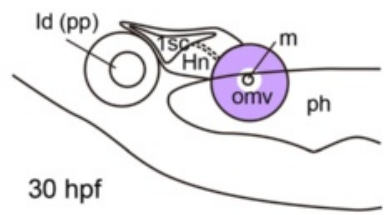

Fig. 2 Developmental pattern of oral mesovesicle. a-d Mouth formation visualized by pou4 expression. Oral mesovesicle initially connects with first somitocoel (arrowhead in $\mathbf{a}$ ) and then into pharynx (arrowhead in b). Perforation of mouth occurs through epidermis and remnant of oral mesovesicle (c, d). e- $\mathbf{g}$ Rendering images of laser confocal microscopic analyses showing expression patterns of pax3/7 and pou4. e1-3 Anterior to the left. Expression of pax $3 / 7$ (orange) in thickened posterior wall of the first somite (arrowheads) from 18 to $30 \mathrm{hpf}$ at $25^{\circ} \mathrm{C}$. f1-3 Expression of pou4 (orange) in bulged wall of the first somite, which transforms into oral mesovesicle (arrowheads) from 18 to $30 \mathrm{hpf}$ at $25^{\circ} \mathrm{C}$. $\mathbf{g 1}-\mathbf{3}$ Outlines of rendering images highlighting expression of two genes. ch, notochord; csg, club-shaped gland; Id, lateral diverticulum; m, mouth; ph, pharynx; pp, preoral pit; 1, 2s, 1st and 2nd somite; 1, 2sc/L or R, left or right first and second somitocoel; pHn/omv, primordium of Hatschek nephridium/oral mesovesicle complex. Scale bars $50 \mu \mathrm{m}$

At the final stage, intercalation occurred between the thinned epidermis and the remnant of the OMV that was regionally restricted to the future perforation site. The opening of the Hatschek nephridium was located dorsal to the mouth opening site (Fig. 3e).

It has been reported that basal laminae in the oral region are positively controlled by Wnt signaling in
Xenopus, whereas Wnt antagonists such as Dickkopf (Dkk) and secreted Frizzled-related proteins function in its dissolution [34]. To determine whether the formation of basal laminae around the OMV is regulated by similar molecular mechanisms to those of vertebrates, we analyzed the expression of the corresponding genes $d k k 1 / 2 / 4$ [35] and frzb1 in Branchiostoma japonicum. 

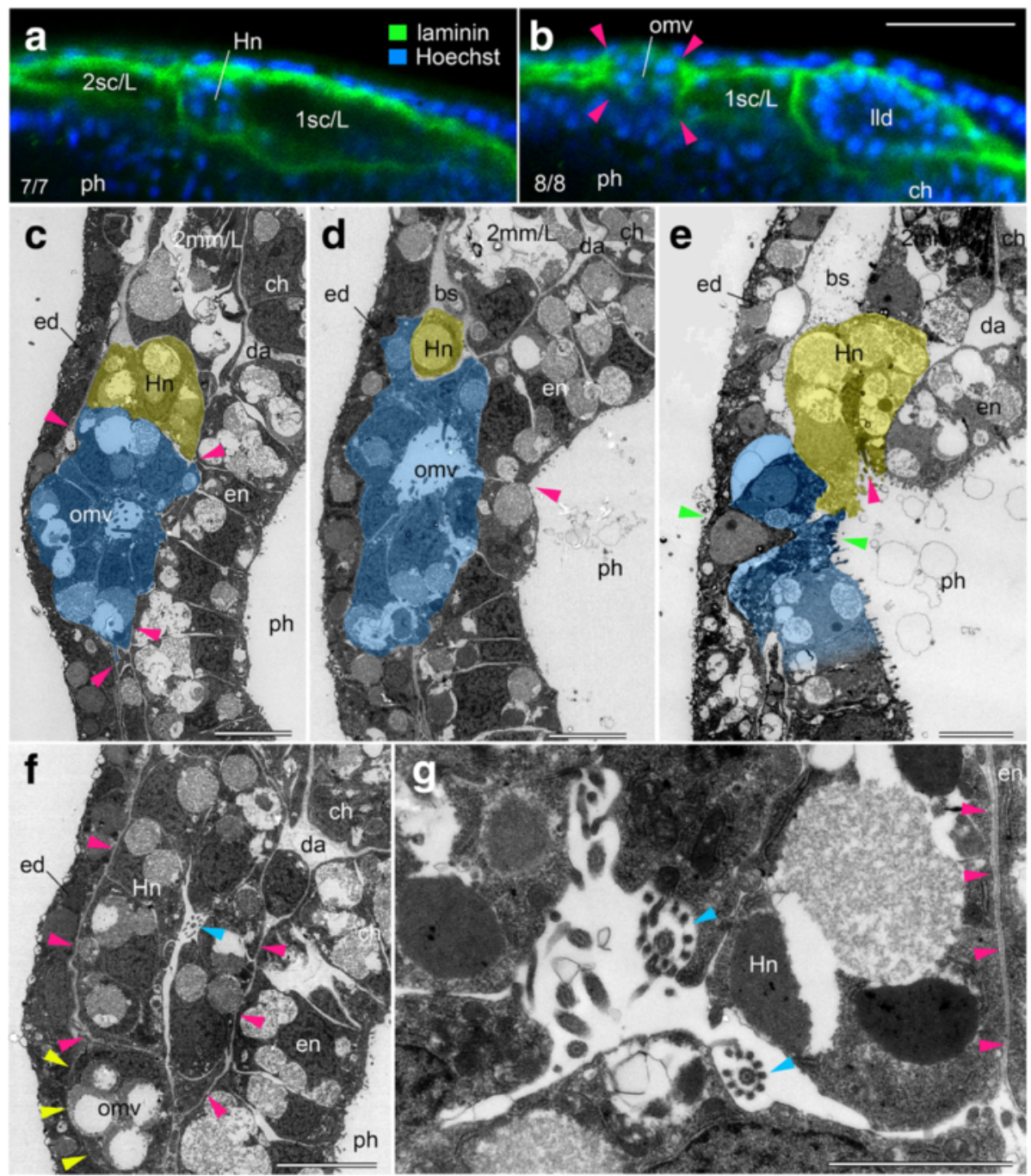

Fig. 3 Oral mesovesicle/Hatschek nephridium complex and basal laminae. a, b Fluorescent horizontal sections showing nuclei and immunolabeling for basal laminae. Note dissolution of basal laminae on oral mesovesicle (arrowheads in $\mathbf{b}$ ). $\mathbf{c}-\mathbf{e}$ Electron micrographs showing transverse sections of developing oral mesovesicle. While primordium of Hatschek nephridium develops basal laminae, oral mesovesicle does not (arrowheads in c). Oral mesovesicle first opens into pharynx without epithelical intercalation (arrowhead in d). Outlet of Hatschek nephridial canal into pharynx (magenta arrowhead in $\mathbf{e}$ ) and site of oral perforation (green arrowheads in $\mathbf{e}$ ). $\mathbf{f}$ Electron micrographs showing transverse sections of Hatschek nephridium with flagellum and whorl of microvilli from a cyrtopodocyte (cyan arrowhead) and basal laminae (magenta arrowheads). There is no basal lamia around oral mesovesicle (yellow arrowheads). $\mathbf{g}$ Magnification of canal of Hatschek nephridium showing two flagella with a whorl of microvilli (cyan arrowheads) and basal lamina between Hatschek nephridium and pharyngeal endoderm (magenta arrowheads). bs, blood sinus; ch, notochord; da, dorsal aorta; ed, epidermis; en, endoderm; Hn, Hatschek nephridium; Ild, left lateral diverticulum; omv, oral mesovesicle; ph, pharynx; 2 mm/L, left 2nd myomere;1-2sc/L, left 1st and 2nd somitocoel. Scale bars $20 \mu \mathrm{m}$ for (a), (b), $5 \mu \mathrm{m}$ for $(\mathbf{c}-\mathbf{f})$, and $2 \mu \mathrm{m}$ for $(\mathbf{g})$

Wnt antagonist-encoding genes were expressed in the left lateral diverticulum and OMV with some extension into surrounding regions (Fig. 4). Although these Wnt antagonists are secreted proteins and the expression domains of the genes encoding these proteins did not show any clear boundaries, the basal laminae in the Hn/OMV complex clearly demarcated between these two components in TEM images (Fig. 3c, f). The Pax2 protein has also been suggested to have a role in the dissolution of basal laminae
[36], and amphioxus gene pax2/5/8 was expressed in the lateral diverticula, OMV, and gills before perforation (Fig. 4 and ref. [37]). These expression patterns suggest that these anterior-specific genes commonly function in epithelial perforations in the chordate head.

When the pan-placode in vertebrates and the median stomodaeum in ascidians are specified, the transcription factor gene pitx is commonly involved [20,38]. Amphioxus embryos also express pitx very weakly and transiently 


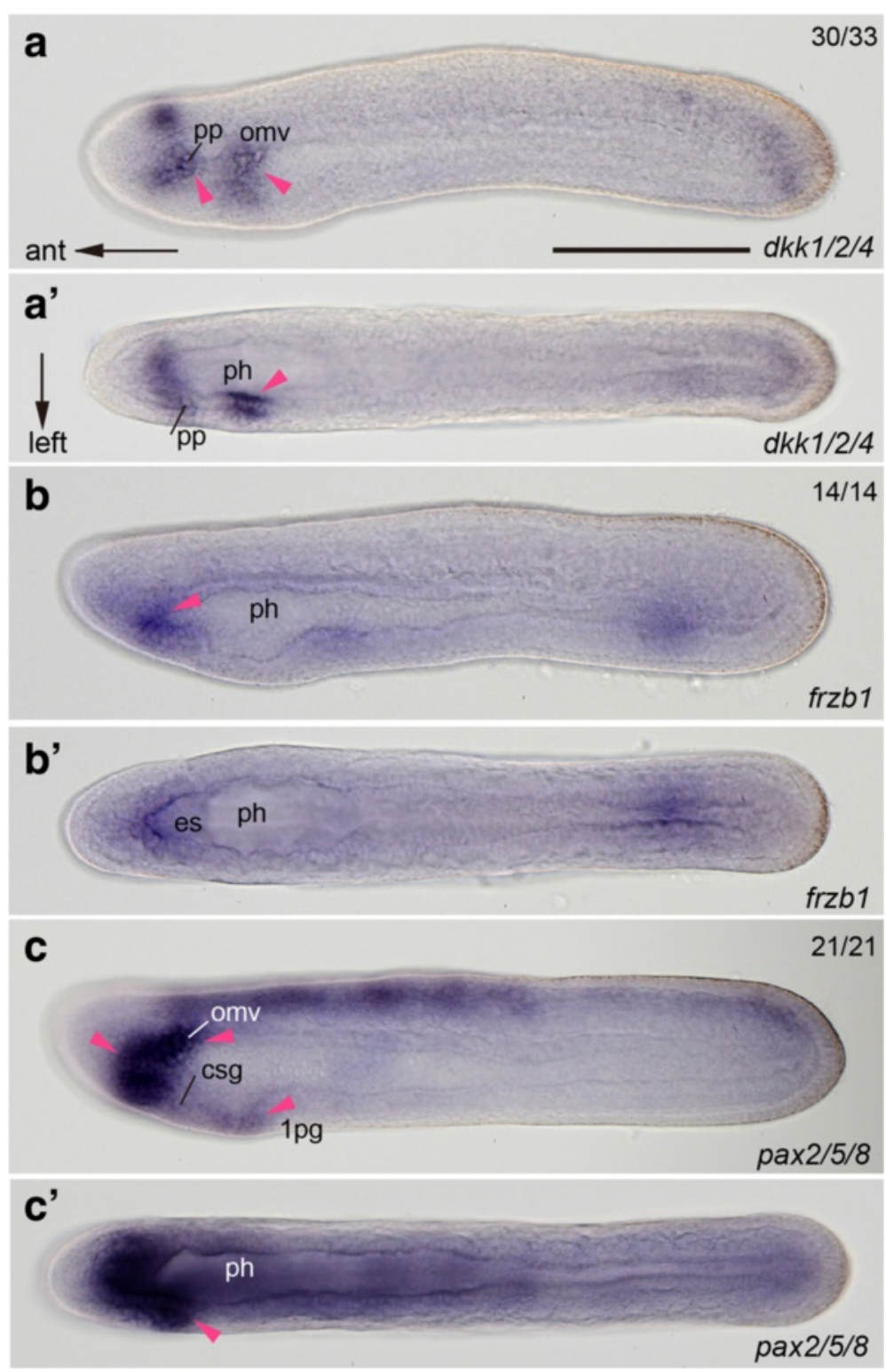

Fig. 4 Expression patterns of antagonistic genes to Wnt and pax2/5/8 related to dissolution of basal laminae. a-c Left lateral views of knife-shaped larvae. $\mathbf{a}^{\prime}-\mathbf{c}^{\prime}$ Dorsal views. Most genes are expressed in the region where internal lumens open into the exterior. Arrowheads denote gene expression regions. csg, club-shaped gland; es, endostyle; omv, oral mesovesicle; 1 pg, future first gill; ph, pharynx; pp, preoral pit. Scale bar, 100 um for all

in the epidermis anterior to the anterior margin of the future neural plate [23]. However, amphioxus embryos rapdily express this gene asymmetrically in the future left first somite, after which the expression expands into surrounding tissues including the overlying epidermis [23]. The pitx expression domain includes the left first somite that develops the OMV and the oral ectoderm. The expression domain of the nodal gene partially overlaps that of pitx [39], and this colocalization suggests their interaction in amphioxus embryos. Moreover, the Nodal-Pitx signaling unit is highly conserved in animals $[16,17]$. We therefore examined the role of pitx gene by blocking Nodal signaling at the prehatching neurula stage $(10 \mathrm{hpf}$ at $25^{\circ} \mathrm{C}$ ) with SB505124 [26]. The treated animals lacked the left-handed expression of pitx, but weak, bilaterally symmetrical signals in the pharynx were found (Fig. 5a, b). The treated animals also displayed a bilaterally symmetrical anatomy (Fig. 5a-d). A similar bilaterally symmetrical morphology has also been reported for B. floridae and $B$. lanceolatum [18, 40]. The endostyle and club-shaped gland, which develop on the right side at the anterior end of the normal pharynx as mucus secreting glands, became 


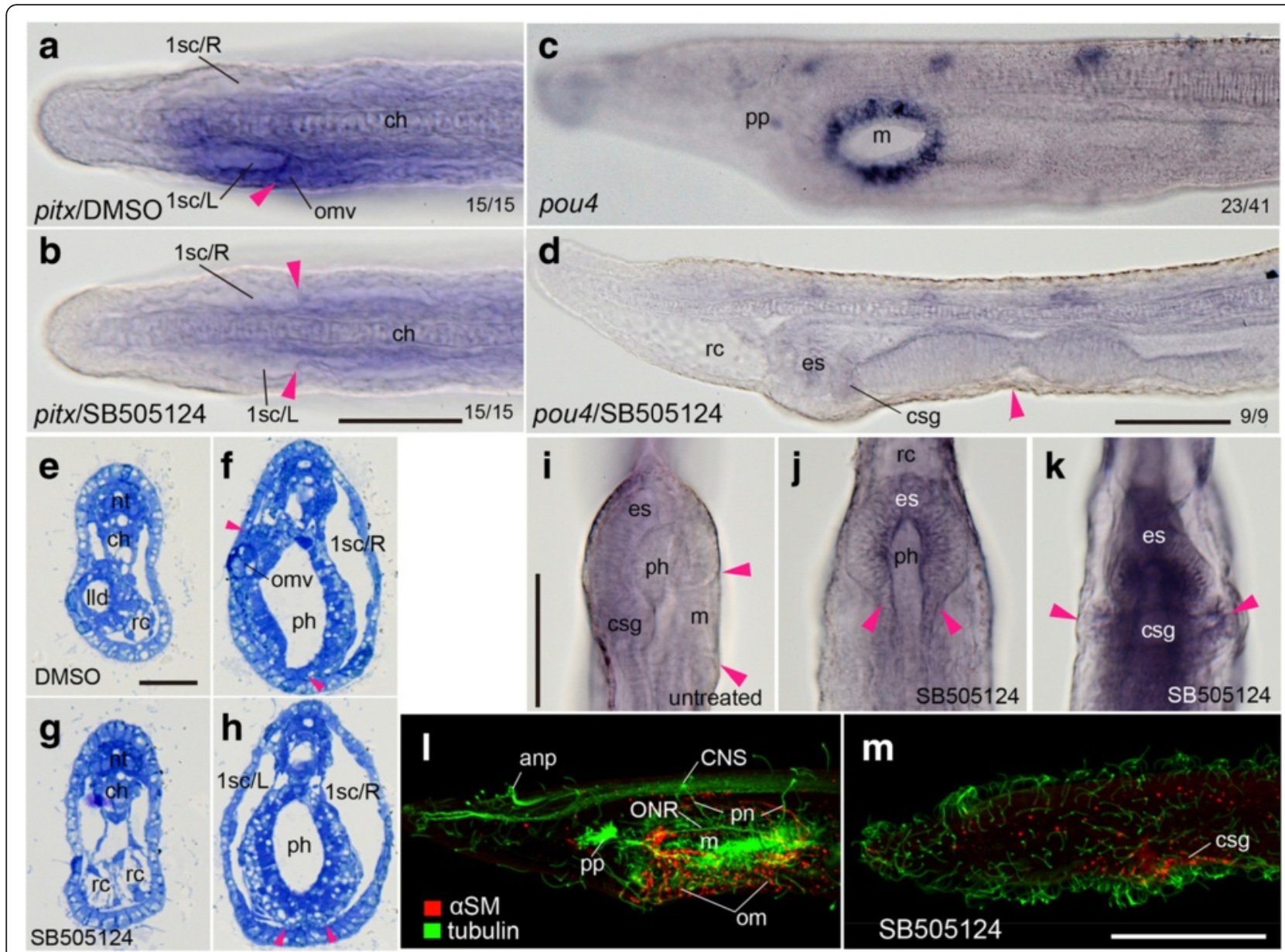

Fig. 5 Bilaterally symmetric development of larvae treated with Nodal signaling inhibitor. a Dorsal view showing pitx expression on left side (arrowhead) of untreated 24-hpf larva. $\mathbf{b}$ Lack of left-handed pitx expression and symmetrical arrangement of somitocoels (arrowheads) in treated larva. c Mouth opening shown with pou4 expression in control 72-hpf larva. d Disappearance of mouth-related expression of pou4 and complete lack of organs originating from left side and domed pharyngeal floor (arrowhead) in treated larva. $\mathbf{e}, \mathbf{f}$ Transverse sections showing future oral regions of control larvae at $24 \mathrm{hpf} . \mathbf{g}, \mathbf{h}$ Transverse sections of treated 24-hpf larva showing bilaterally symmetric internal structures with a pair of rostral coeloms. Levels are comparable between $(\mathbf{e})$ and $(\mathbf{g})$ and $(\mathbf{f})$ and $(\mathbf{h})$, respectively. No oral mesovesicle but somitocoel on left side almost identical to that on right side in treated larvae (compare arrowheads between $\mathbf{f}$ and $\mathbf{h}$ ). i Ventral view of normal pharynx with mouth opening (arrowheads). j, k Ventral views of treated pharynx showing bilaterally symmetric endostyle and club-shaped gland (arrowheads). i-k are shown with background of BM purple to clarify morphological details. I, $\mathbf{m}$ Immunolabeling for ventral muscles and acetylated tubulin. Left lateral views showing untreated larvae (72 hpf) (I) and SB505124-treated larvae with lack of neurons and oral musculature (66 hpf) (m). anp, anterior neuropore; csg, club-shaped gland; ch, notochord; CNS, central nervous system; es, endostyle; lld, left lateral diverticulum; m, mouth; nt; nerve cord; om, oral muscle; omv, oral mesovesicle; ONR, oral nerve ring; ph, pharynx; pn, peripheral nerve; pp, preoral pit; rc, rostral coelom; 1sc/L or R, first left or right somitocoel. Scale bars $50 \mu \mathrm{m}$ for $(\mathbf{a}-\mathbf{d}), 20 \mu \mathrm{m}$ for $(\mathbf{e}-\mathbf{h}), 100 \mu \mathrm{m}$ for the others

bilaterally symmetric. In contrast, structures that normally develop on the left side, such as the preoral pit, the outlet of the club-shaped gland, and the mouth, were entirely absent (Fig. 5c, d, i-k). Histological observations of the treated larvae confirmed that the first somites on both sides were identical. The left first somite produced neither OMV nor Hn, but instead extended towards the ventral midline and produced the left rostral coelom as the rightside counterpart normally would do (Fig. 5e-h). In 72-hpf larvae that normally developed well-defined mouths, there were no traces of mouth or gill pore development, and instead the pharyngeal floor became domed when treated with the inhibitor (Fig. 5c, d). Although normal larvae develop an oral nerve plexus and muscles [41, 42], neither muscular nor neuronal development was immunohistochemically detected in the oral region of the treated larvae (Fig. 5l, m).

The interruption of the Nodal signaling resulted in the complete absence of the Hn and OMV, and thus we investigated the developmental capability of the $\mathrm{Hn}$ / OMV complex by examining expression patterns of nephridium specific gene lim1/5 [30]. While control 
neurula embryos $\left(16 \mathrm{hpf}\right.$ at $\left.25^{\circ} \mathrm{C}\right)$ expressed $\lim 1 / 5$ in the posterior wall of the left first somite, treated embryos showed no expression in the same region (Fig. 6). This suggests that the formation of the mouth and $\mathrm{Hn}$ are controlled by the left-handed expression of pitx or widely downstream target genes of the Nodal signaling.
Ambulacrarian coeloms are reported to contribute to excretion, and thus the coelom needs to open to the exterior [43]. Ambulacrarians extend a canal or a pair of canals from a coelom to form a coelomic pore-canal (hydropore) unilaterally or bilaterally [43]. The ambulacrarian coelomic pore-canal expresses bmp2/4 [44], and

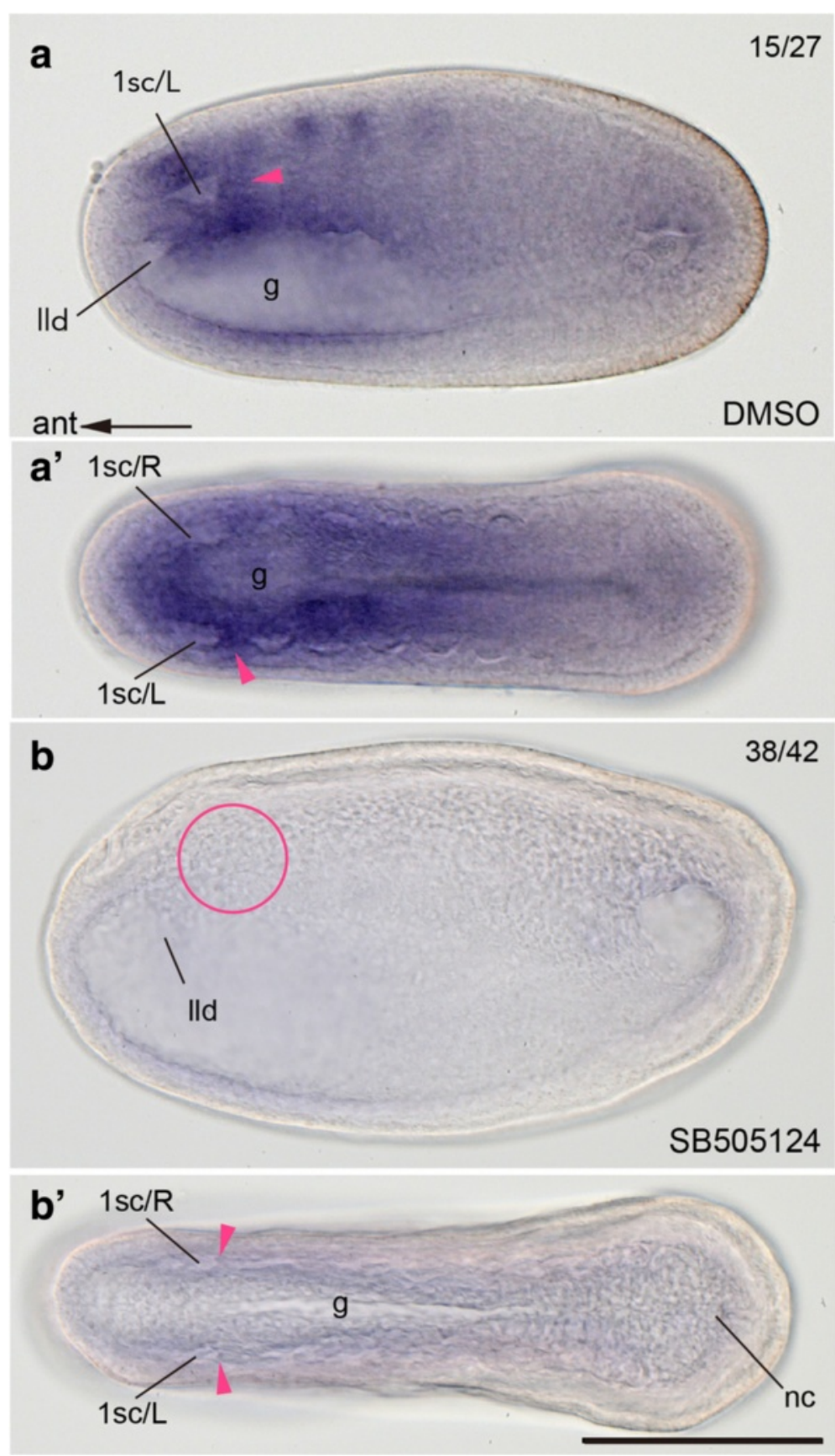

Fig. 6 Loss of nephrogenic capability in embryos treated with Nodal signaling inhibitor. a, a' Left lateral (a) and dorsal (a') views of control hatched-neurula showing lim 1/5 expression in posterior wall of left first somite (arrowheads). $\mathbf{b}, \mathbf{b}^{\prime}$ Loss of corresponding expression in treated neurula (circle and arrowheads) viewed left laterally (b) and dorsally (b'). g, gut; lld, left lateral diverticulum; nc, neurenteric canal; $1 \mathrm{sc} / \mathrm{L}$ or R, first left or right somitocoel. Scale bar, $100 \mu \mathrm{m}$ for all 
the hydropore does not form in sea urchins if Bmp2/4 signaling is blocked by the inhibitor Dorsomorphin [45]. B. japonicum also expressed bmp $2 / 4$ transiently in a small region of the $\mathrm{OMV}$ in tight contact with the epidermis (Fig. 7a, b). We treated larvae with Dorsomorphin prior to the mouth opening and found that this inhibitor also affected the mouth formation in amphioxus in a dose-dependent manner. Like the hydropore of sea urchins, the treatment led to no mouth opening and no oral muscle development (Fig. 7c-i).

The present study confirms the close association of the mouth development with the Hn in amphioxus. This may support a serial homology between the amphioxus mouth and gill slits [11] as each paired gill slit also associates with branchial nephridium (Bn) [46]. Like the Hn/ OMV complex, Bns open into the pharynx, and gills form

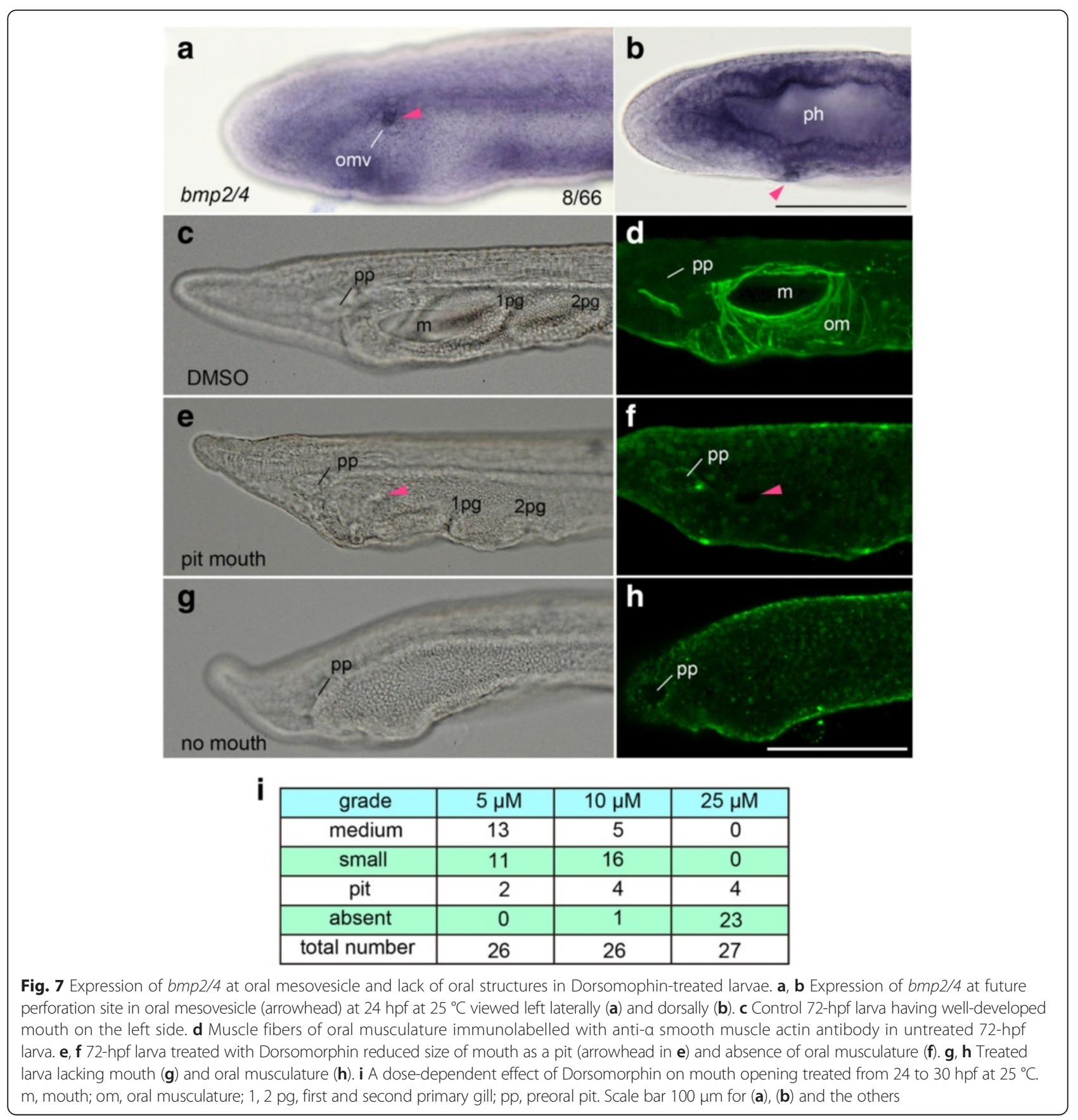


through this opening by perforating ectoderm-mesoderm and endoderm-mesoderm bi-layered membranes (Fig. 8) [46]. Despite this similarity, we favor the idea that the amphioxus mouth and ambulacrarian coelomic porecanal originate from a shared genetic background established in a common ancestor (Fig. 9) because the developmental timing relative to surrounding tissues shows a large disparity between the $\mathrm{Hn}$ and Bns. The Hn develops during early larval stages, whereas all Bns develop during metamorphosis and onward as paired gill openings. The similarity between the amphioxus mouth and paired gill openings rather suggests that these developmental mechanisms retain an ancestral state that offers an insight into the origin of pharyngeal gill slits in the deuterostome ancestor, a question that remains unexplored.

Dorso-ventral inversion is not only an issue of body axes, but also of mouth formation. Gene expression analyses suggest that a dorso-ventral inversion occurred in deuterostomes, possibly in a chordate ancestor [8]. When chordates acquired dorsal structures such as the notochord and epithelial neural tube, they utilized a signaling center at the dorsal margin of the blastopore with GRN including nodal, goosecoid, chordin, and brachyury. Interestingly, the chordate dorsalizing GRN is comparable to that determining the oral side of sea urchin embryos [47]. If this similarity is related to the dorso-ventral inversion, chordates needed a new means of mouth formation. Gastrulation in chordates permits new mouth formation by having the developing primitive gut underlie the epiblast (outer layer), especially in the anterior region, contrary to ambulacrarian gastrulation, in which the primitive gut does not fill the blastocoel or rapidly differentiate a protocoel at the anterior end in some enteropneust embryos [48, 49]. To open a new mouth, olfactoreans (urochordates + vertebrates) developed an anterior placode or stomodaeum under a median Pitx function [20,38], whereas amphioxus utilizes an ancestral coelomic canal coupled with the early Pitx function on the anterior left side, probably owing to the inability to form placodes [50]. In mouth formation, the Nodal-Pitx signaling unit has likely been co-opted variously as this unit is also utilized in the molluscan stomodaeum [51]. The amphioxus mouth does not represent an ancestral condition of the vertebrate mouth, but instead may display a close relationship to the deep origin of gill openings in deuterostomes.

\section{Conclusions}

We have studied the development of the amphioxus mouth that initially opens on the left lateral side of the

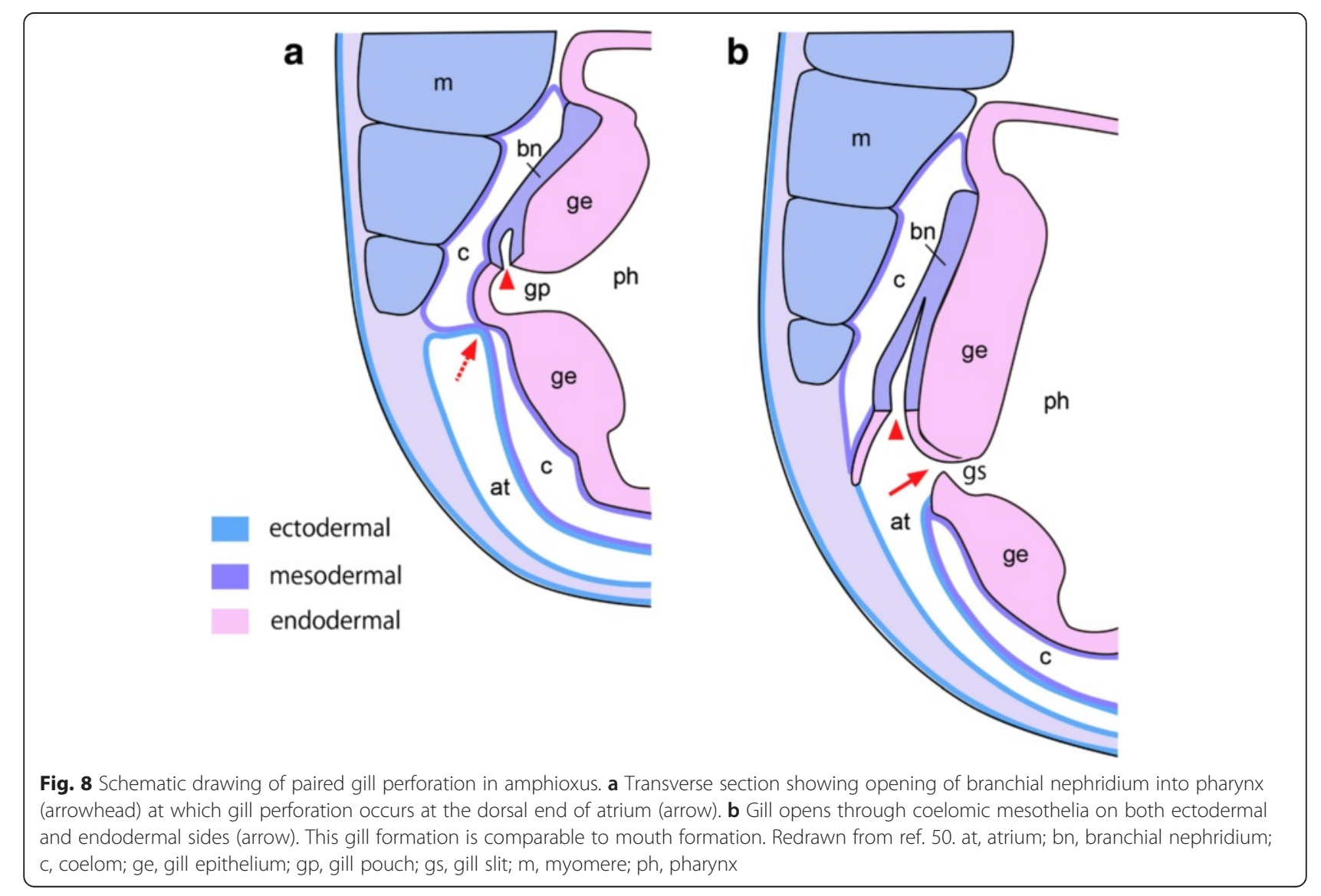




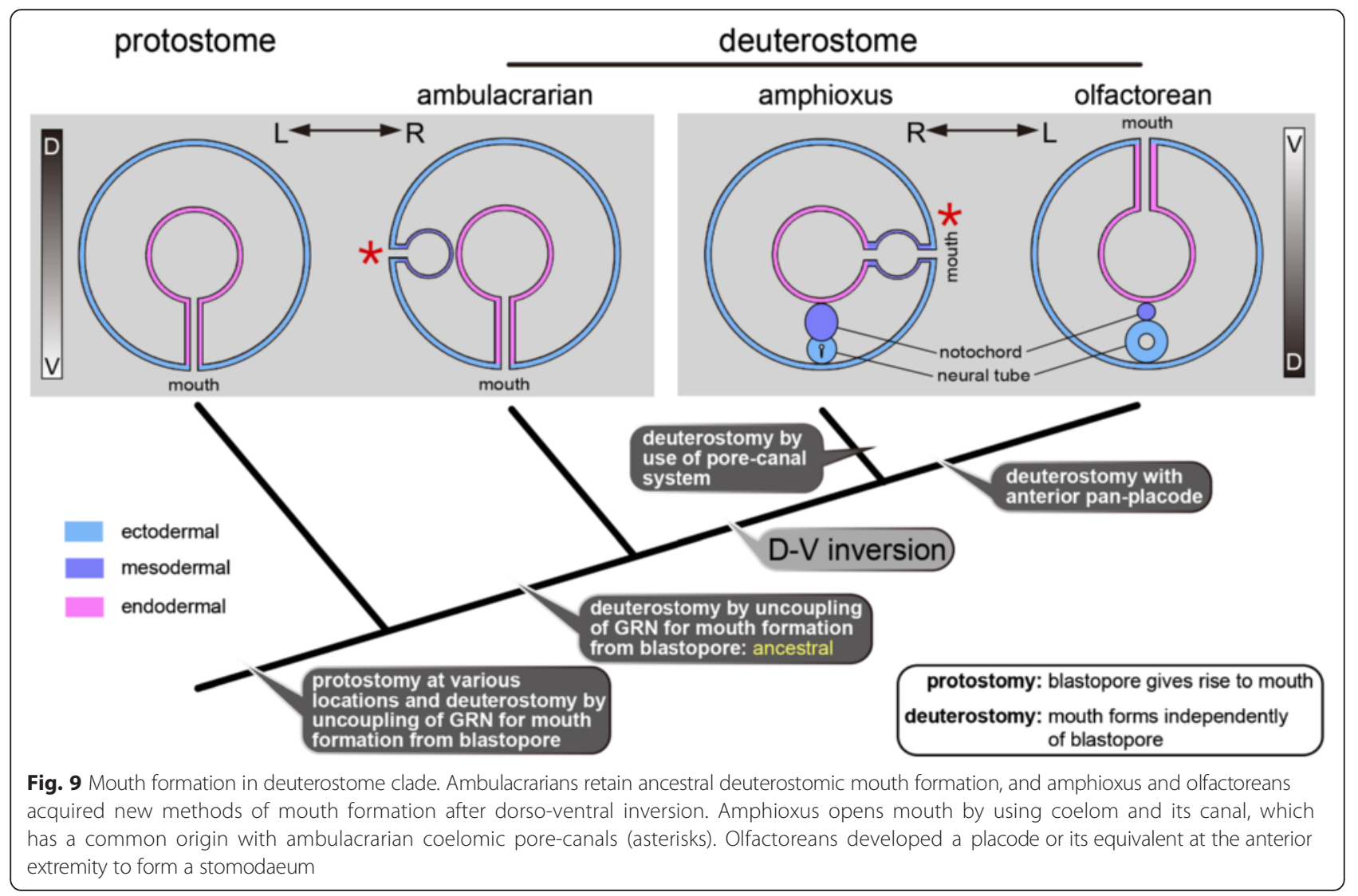

pharynx. The unusual location of the amphioxus mouth is caused by unique development that involves the coelomic mesoderm. We conclude that the opening of the amphioxus mouth is mediated by a coelomic vesicle (OMV) that develops from the posterior ventral corner of the left first somite in association with the Hatschek nephridium. This OMV development is controlled by the Nodal-Pitx unit that gives rise to the left-right asymmetrical development. The developmental pattern of the amphioxus mouth leads us to hypothesize on the common evolutionary origin of the amphioxus mouth and ambulacrarian pore-canals. This unique mouth is parsimoniously regarded an apomorphic character most likely acquired at the appearance of the amphioxus lineage and has no relation to the olfactorean mouths. As the olfactorean group also develops a mouth under a GRN different from that in ambulacrarians, which is likely ancestral in chordates, we also hypothesize that new chordate mouths were acquired in relation to the dorsoventral inversion that occurred in the last common ancestor of chordates.

\section{Competing interests}

The authors declare that they have no competing interests.

\section{Authors' contributions}

TK, ARM, and KY performed sample collection. TK performed the pharmacological treatments with SB505124 and Dorsomorphin. TK and ARM cloned all genes except bmp2/4 and performed whole-mount in situ hybridization. KY performed histological sections and preparation for transmission electron microscopy. KY prepared all figures. KY, JDR, SK, and TK wrote the manuscript. All authors read and approved the final manuscript.

\section{Acknowledgments}

We thank Y. Henmi of Kumamoto University for the generous acceptance of the amphioxus culture; A. Maenaka, K. Shiohira, and H. Shimasaki of Kumamoto University for collecting wild amphioxus and daily care of the amphioxus colony; and K. Koike of Hiroshima University for transmission electron microscopic images. We also thank K. B. Artinger of University of Colorado Denver and Y. Yaoita of Hiroshima University for their critical reading of the manuscript.

\section{Author details}

'Department of Biological Science, Graduate School of Science, Hiroshima University, 1-3-1 Kagamiyama, Higashi-hiroshima, Hiroshima 739-8526, Japan. ${ }^{2}$ Present address: Department of Diabetes Technology, Graduate School of Biomedical Engineering, Tohoku University, 6-6-12 Aramaki Aza Aoba, Aoba-ku, Sendai, Miyagi 980-8579, Japan. ${ }^{3}$ Department of Biology, Chemistry and Marine Sciences, Faculty of Science, University of the Ryukyus, 1 Senbaru, Nishihara, Okinawa 903-0213, Japan. ${ }^{4}$ Department of Zoology and General Biology, Institute of Fundamental Medicine and Biology, Kazan (Volga Region) Federal University, 18 Kremlyovskaya St., Kazan 420008, Republic of Tatarstan, Russian Federation. ${ }^{5}$ Evolutionary Morphology Laboratory, RIKEN, 2-2-3 Minatojima-minami, Chuo-ku, Kobe, Hyogo 650-0047, Japan. 


\section{Received: 14 August 2015 Accepted: 3 February 2016}

\section{Published online: 06 February 2016}

\section{References}

1. Lee $P N$, Kumburegama S, Marlow $H Q$, Martindale MQ, Wikramanayake AH. Asymmetric developmental potential along the animal-vegetal axis in the anthozoan cnidarian, Nematostella vectensis, is mediated by Dishevelled. Dev Biol. 2007;310:169-86.

2. Hejnol A, Martindale MQ. The mouth, the anus, and the blastopore - open questions about questionable openings. In: Telford MJ, Littlewood DTJ, editors. Animal Evolution: Genomes, Fossils, and Trees. Oxford: Oxford Univ Press; 2009. p. 33-40.

3. van den Biggelaar J, Dictus WJAG. Gastrulation in the molluscan embryo. In: Stern CD, editor. Gastrulation: From Cells to Embryo. Cold Spring Harbor: Cold Spring Harbor Laboratory Press; 2004. p. 63-78.

4. Hejnol A, Schnabel R. The eutardigrade Thulinia stephaniae has an indeterminate development and the potential to regulate early blastomere ablations. Development. 2004;132:1349-61.

5. Hejnol A, Martindale MQ. Acoel development indicates the independent evolution of the bilaterian mouth and anus. Nature. 2008:456:382-6.

6. Arendt D, Technau U, Wittbrodt J. Evolution of the bilaterian larval foregut. Nature. 2001;409:81-5.

7. Dickinson A, Sive H. Positioning the extreme anterior in Xenopus: cement gland, primary mouth and anterior pituitary. Sem Cell Dev Biol. 2007;18:525-33.

8. Lowe CJ, Terasaki M, Wu M, Freeman Jr RM, Runft L, Kwan K, et al. Dorsoventral patterning in hemichordates: Insights into early chordate evolution. PLoS Biol. 2006;: :e291.

9. Legros R. Sur quelque points de l'anatomie et du développement de I'Amphioxus. Anat Anz. 1910;35:561-87.

10. van Wijhe JW. Beiträge zur Anatomie der Kopfregion des Amphioxus lanceolatus. Petrus Camper. 1901;1:109-94.

11. Ruppert EE. Morphology of Hatschek's nephridium in larval and juvenile stages of Branchiostoma virginiae (Cephalochordata). Isr J Zool. 1996;42 Suppl 1:161-82.

12. MacBride EW. The formation of the layers in amphioxus and its bearing on the interpretation of the early ontogenetic processes in other vertebrates. Q J Micr Sci. 1909;54:279-345.

13. Willey A. Amphioxus and the Ancestry of Vertebrates. Osborn HF, editors. New York: Macmillan; 1894. p. 1-316.

14. Medawar PB. Asymmetry of larval Amphioxus. Nature. 1951;167:852-3.

15. Yasui K, Kaji T. The lancelet and ammocoete mouths. Zool Sci. 2008;25:1012-9.

16. Grande C, Martín-Durán JM, Kenny NJ, Truchado-García M, Hejnol A. Evolution, divergence and loss of the Nodal signaling pathway: new data and a synthesis across the Bilateria. Int J Dev Biol. 2014;58:521-32.

17. Watanabe H, Schmidt HA, Kuhn A, Höger SK, Kocagöz Y, Laumann-Lipp N, et al. Nodal signaling determines bilateral asymmetry in Hydra. Nature 2014:515:112-5.

18. Vladimir Soukup V, Yong LW, Lu TM, Huang SW, Kozmik Z, Yu JK. The Nodal signaling pathway controls left-right asymmetric development in amphioxus. EvoDevo. 2015;6:5. doi:10.1186/2041-9139-6-5.

19. Jefferies RPS. Two types of bilateral symmetry in the Metazoa: Chordate and bilaterian. In: Bock GR, Marsh J, editors. Biological Asymmetry and Handedness. Chichester: Wiley; 1991. p. 94-127.

20. Christiaen L, Bourrat F, Joly JS. A modular cis-regulatory system controls isoform-specific Pitx expression in the ascidian stomodaeum. Dev Biol. 2005;277:557-66.

21. Zhang Q, Zhong J, Fang S, Wang Y. Branchiostoma japonicum and B. belcheri are distinct lancelets (Cephalochordata) in Xiamen waters in China. Zool Sci. 2006;23:573-9.

22. Yasui K, Igawa T, Kaji T, Henmi Y. Stable aquaculture of the Japanese lancelet Branchiostoma japonicum for 7 years. J Exp Zool (Mol Dev Evol). 2013;320B:538-47.

23. Yasui $K$, Zhang SC, Uemura $M$, Saiga $H$. Left-right asymmetric expression of BbPtx, a Ptx-related gene, in a lancelet species and the developmenta left-sidedness in deuterostomes. Development. 2000;127:187-95.

24. Wu H, Chen Y, Su Y, Luo Y, Holland LZ, Yu J. Asymmetric localization of germline markers Vasa and Nanos during early development in the amphioxus Branchiostoma floridae. Dev Biol. 2011;353:147-59.

25. Yasui K, Tabata S, Ueki T, Uemura M, Zhang S. Early development of the peripheral nervous system in a lancelet species. J Comp Neurol. 1998;393:415-25.
26. DaCosta Byfield S, Major C, Laping NJ, Roberts AB. SB-505124 is a selective inhibitor of transforming growth factor- $\beta$ type 1 receptors ALK4, ALK5, and ALK7. Mol Pharmacol. 2004;65:744-52.

27. Shimizu K, Sarashina I, Kagi H, Endo K. Possible functions of Dpp in gastropod shell formation and shell coiling. Dev Gene Evol. 2011;221:59-68.

28. Candiani S, Oliveri D, Parodi M, Bertini E, Pestarino M. Expression of AmphiPOU$N$ in the developing neural tube and epidermal sensory neural precursors in amphioxus supports a conserved role of class IV POU genes in the sensory cells development. Dev Gene Evol. 2006;216:623-33.

29. Hammond CL, Hinits Y, Osborn DPS, Minchin JEN, Tettamanti G, Hughes SM, et al. Signals and myogenic regulatory factors restrict pax3 and pax7 expression to dermomyotome-like tissue in zebrafish. Dev Biol. 2007; 302:504-21.

30. Langeland JA, Holland LZ, Chastain RA, Holland ND. An amphioxus LIM-homeobox gene, AmphiLim 1/5, expressed early in the invaginating organizer region and later in differentiating cells of the kidney and central nervous system. Int J Biol Sci. 2006;2:110-6.

31. Stach T, Eisler K. The ontogeny of the nephridial system of the larval amphioxus (Branchiostoma lanceolatum). Acta Zool (Stockholm). 1998; 79:113-8.

32. Kümmel G. Zwei neue Formen von Cyrtocyten. Vergleich der bisher bekannten Cyrtocyten und Erörterung des Begriffes "Zelltyp". Z Zellforsch. 1962;62:468-84.

33. Goodrich ES. The early development of the nephridia in amphioxus: introduction and part I, Hatschek's nephridium. Q J Micr Sci. 1934;76:499-510.

34. Dickinson AJG, Sive H. The Wnt antagonists Frzb-1 and Crescent locally regulate basement membrane dissolution in the developing primary mouth. Development. 2009;136:1071-81.

35. Zhang Y, Mao B. Embryonic expression and evolutionary analysis of the amphioxus Dickkopf and Kremen family genes. J Genet Genomics. 2010;37:637-45.

36. Edelman GM, Jones FS. Developmental control of N-CAM expression by Hox and Pax gene products. Phil Trans Roy Soc Lond B. 1995;349:305-12.

37. Kozmik Z, Holland ND, Kalousova A, Paces J, Schubert M, Holland LZ. Characterization of an amphioxus paired box gene, AmphiPax2/5/8: developmental expression patterns in optic support cells, nephridium, thyroid-like structures and pharyngeal gill slits, but not in the midbrainhindbrain boundary region. Development. 1999;126:1295-304.

38. Oisi Y, Ota KG, Kuraku S, Fujimoto S, Kuratani S. Craniofacial development of hagfishes and the evolution of vertebrates. Nature. 2013;493:175-80.

39. Yu J-K, Holland LZ, Holland ND. An amphioxus nodal gene (AmphiNodal) with early symmetrical expression in the organizer and mesoderm and later asymmetrical expression associated with left-right axis formation. Evo Dev. 2003:4:418-25.

40. Bertrand S, Aldea D, Oulion S, Subirana L, de Lera AR, Somorjai I, et al. Evolution of the role of RA and FGF signals in the control of somitogenesis in chordates. PLOS ONE. 2015;10:e0136587.

41. Lacalli TC, Gilmour THJ, Kelly SJ. The oral nerve plexus in amphioxus larvae: function, cell types and phylogenetic significance. Proc R Soc Lond B. 1999;266:1461-70.

42. Yasui K, Kaji T, Morov AR, Yonemura S. Development of oral and branchial muscles in lancelet larvae of Branchiostoma japonicum. J Morphol. 2014;275:465-77.

43. Ruppert EE, Balser EJ. Nephridia in the larvae of hemichordates and echinoderms. Biol Bull. 1986;171:188-96.

44. Harada Y, Shoguchi E, Taguchi S, Okai N, Humphreys T, Tagawa K, et al. Conserved expression pattern of BMP-2/4 in hemichordate acorn worm and echinoderm sea cucumber embryos. Zool Sci. 2002;19:1113-21.

45. Luo Y, Su Y. Opposing Nodal and BMP signals regulate left-right asymmetry in the sea urchin larva. PLoS Biol. 2012;10:e1001402.

46. Goodrich ES. The early development of the nephridia in amphioxus: Part II, the paired nephridia. Q J Micr Sci. 1934;76:655-74.

47. Molina MD, de Crozél N, Emmanuel Haillot E, Lepage T. Nodal: master and commander of the dorsal-ventral and left-right axes in the sea urchin embryo. Cur Opi Gen Dev. 2013;23:445-53.

48. Röttinger $E$, Martindale MQ. Ventralization of an indirect developing hemichordate by $\mathrm{NiCl}_{2}$ suggests a conserved mechanism of dorso-ventral (D/N) patterning in Ambulacraria (hemichordates and echinoderms). Dev Biol. 2011;354:173-90.

49. Röttinger $E$, DuBuc TQ, Amiel AR, Martindale MQ. Nodal signaling is required for mesodermal and ventral but not for dorsal fates in the indirect 
developing hemichordate, Ptychodera flava. Biol Open. 2015;00:1-13. doi:10.1242/bio.011809.

50. Meulemans D, Bronner-Fraser M. The amphioxus SoxB family: Implications for the evolution of vertebrate placodes. Int J Biol Sci. 2007;3:356-64.

51. Grande C, Patel NH. Nodal signalling is involved in left-right asymmetry in snails. Nature. 2009:457:1007-11.

52. Putnam NH, Butts T, Ferrier DEK, Furlong RF, Hellsten U, Kawashima T, et al. The amphioxus genome and the evolution of the chordate karyotype. Nature. 2008:453:1064-71.

53. Zhang Y, Wang LF, Shao M, Zhang HW. Characterization and developmental expression of AmphiMef2 gene in amphioxus. Sci China Ser C-Life Sci. 2007;50:637-41.

54. Hiruta J, Mazet F, Yasui K, Zhang P, Ogasawara M. Comparative expression analysis of transcription factor genes in the endostyle of invertebrate chordates. Dev Dyn. 2005:233:1031-7.

55. Holland LZ, Schubert M, Kozmik Z, Holland ND. AmphiPax3/7, an amphioxus paired box gene: insights into chordate myogenesis, neurogenesis, and the possible evolutionary precursor of definitive vertebrate neural crest. Evo Dev. 1999;1:153-65.

Submit your next manuscript to BioMed Central and we will help you at every step:

- We accept pre-submission inquiries

- Our selector tool helps you to find the most relevant journal

- We provide round the clock customer support

- Convenient online submission

- Thorough peer review

- Inclusion in PubMed and all major indexing services

- Maximum visibility for your research

Submit your manuscript at www.biomedcentral.com/submit
Biomed Central 